\title{
STATISTICAL MODELING OF OPTIMAL DEVELOPMENT STRATEGY AND UPGRADE OF INTERNET TRADING QUALITY SYSTEM IN TRANSITION COUNTRIES
}

\author{
Mirjana Landika ${ }^{1}$ \\ Radmila Bojanić ${ }^{2}$
}

\author{
1Paneuropean University „Apeiron“ \\ Banja Luka, \\ Banja Luka, Republic of Srpska, B\&H \\ ${ }^{2}$ M:tel a.d. Banja Luka, \\ Banja Luka, Republic of Srpska, B\&H
}

\section{Correspondence:}

Radmila Bojanić

e-mail:

radmila.bojanic@mtel.ba

\begin{abstract}
:
Observing and studying the economic system as a totality of business entities at a global level is justified. The constitution of such a system implies that the events in one system segment reflect on the system as a whole.

The inspiration and challenge for numerous researchers encompasses the attempts to comprehend forms, directions and nature of correlation of the phenomenon within the global system. The economic system goes through the phase of global connecting through the World Wide Web, where, among others, a new form of goods for cash exchange has developed, known as electronic trading or internet trading.

The stochastic character of development processes of individual market segments is visible both in the degree and direction of quantitative matching of variations of certain appearances and processes, in reference to connectivity of certain appearances and processes in individual system segments.

According to Marc Porter, development and upgrading of the quality system, as a set of adequate development strategies of business systems are realized, among other things, by market focusing (Todorović, 2001). The aforementioned implies that the optimal strategy for development of operations of individual system elements must be adjusted to the earning conditions in the observed market segment.

Identification of factors that set the conditions for the intensity, form and direction of correlation of processes and appearances, their quantification and interpretation, deduced from empirical structure, enables establishing, maintaining and upgrading the quality level in business processes, such as internet trading in transition countries, such as Bosnia and Herzegovina.
\end{abstract}

Key words:

internet trading or online trading, global system, stochastic processes, statistical modelling, development and upgrading of quality system.

\section{INTRODUCTION}

Efficient functioning of business systems implies minimization of differences between the desired and realized results of the selected activity, whereby conditionality of the business result is determined by numerous factors, whose manifestation, even in identical business fields, displays significant differences in various segments of the global economic system.

The achieved development of internet trade on the global level is becoming ever more present and current, with the transition countries lagging significantly behind the development countries. This also represents the hypothetical framework of the research project. 
Factors affecting the concept of functioning of internet trading have a stochasticity dimension, which makes their explicit expressing more difficult in the sense of form and measure of their quantitative matching. The ability of a manager is to recognize through empirical analysis and to interpolate their impact of certain factors through adequate metrics into the business result calculation, in order to optimize the business result adjusted to system units within the global system, despite their stochastic specifics.

Measuring of process performances implies adequate application of methodological procedures of correlation analysis which is used to test the reactivity of achieved satisfaction level of users. Methodology efficiency implies consideration of harmony between user satisfaction, as a dependant variable, and factors, which may be justly assumed to determine the user satisfaction level, as independant variables. The methodology implies calculation and statistical testing of the coefficient of correlation between frequency rank of using internet trading and user perception concerning internet trading quality level.

Experiment design starts with the assumption that in the total population of potential users on the territory of Bosnia and Herzegovina, there is a small number of those who opt for internet trading despite its competent advantages and global development. Examining the samples of such a local trend enables its efficient elimination, through minimization of the gap between the desired and realized result level in the selected system segment, with necessary maximization of user satisfaction, based on the adequate empirical analysis.

\section{UNDERSTANDING THE QUALITY OF SERVICE IN INTERNET TRADING PROCESS}

From the competition perspective, value is an amount that the users are prepared to pay for something offered by internet trading. Value is measured by total profit, which reflects the price dictated by the product of internet trading and quantity it is able to sell. Internet trading is profitable if the value it dictates exceeds the costs. The aim of any generic strategy is to create value for the user which exceeds relevant costs. Value, rather than costs, must be used in the analysis of competitor position, as the internet trading often increased their costs intentionally in order to dictate the premium price on the basis of differentiation.

The activities creating internet trading value represent special elements of competitive advantage. The manner in which each activity is performed together with its economy, determine whether internet trading has high or low costs in relation to its competitors. The manner in which each of those activities is performed will also determine its contribution to the user needs, thereby determining the diferentiation. Comparison of competitor value reveals the differences which determine competitive advantage.

The internet trading services, presented through the purchased product and product price, are value for the user. If that value does not meet the demands and expectations of users at first glance at the time of takeover of the purchased product or its later use, we have a shattered value chain and a negative user experience.

The news about of negative user experience spread fast and users become more cautions with a change of perception towards this manner of trading.

In order for internet trading to maintain the quality level of its services, it must work constantly on its basic operational functions defined through trust, speed, data safety, availability and user satisfaction. Its differentiation results from the relation between its and user understanding of value in all contact points between the buyer value chain and internet trading value chain. Any of the contact points may be the source of differentiation. "Quality" is not a wide enough term for what makes internet trading unique, as it focuses the attention on the product instead on a line of activities which create value and affect the user.

Therefore, differentiation basically results from the value which is created for the user on the basis of impact of internet shopping on its value chain. Value is created when internet trading creates a competitive advantage for the user - reduces his costs, improves his efficiency or predicts future needs, through the analysis of his previous purchases. However, in order to reach a premium price, the user must realize the value is created for him. This means that the internet trading should explain its value to users through advertizing on its internet page and through direct contact with users. The manner in which this value is divided between the internet trading (premium price) and the user (larger profit, more satisfaction for the paid money, higher level of service quality), reflects on the quality and further use of this form of shopping.

\section{ADJUSTING QUALITATIVE METRICS AND ASPECTS OF DISPLAYING BY LEVEL OF SATISFACTION AND USER AFFECTION TO- WARDS SERVICES OF INTERNET TRADING}

Probabilistic judgements of inferential analysis of stochastic processes require a subtle approach to selection of sample for passing judgements and conclusions based on incomplete information. The efficiency of conducted 
analysis is determined by "planned reliability and precision of obtained results of the analysis, as well as by the degree of variability of appearances and processes whose behaviour we are examining" (Landika, 2015).

Expressing the causality of preference of choice of interned trading as a distribution channel, and subjective perception through the quality of realized service, as a dependant variable value, is achieved relatively easily, simply, at a low cost and up-to-date through surveying the population of the wider Banjaluka region as potential users of internet trading.

The questionaire used to collect adequate empirical structure is formed in such a manner to include questions which will adequately clarify the problem being analyzed. The potential users of internet trading, as distribution channel, include active internet service users in business or private correspondence, as the testing population from which a sample of 95 respondents is selected. The selected sample is adjusted to the variability of tested phenomenon, desired reliability and precision of judgements and conclusions resulting from the used models of descriptive and inferential statistical analysis.

The survey questionaires are delivered to survey respondents through electronic mail, where the coverage of space of elementary events is achieved through a concise approach to question formulation procedure, by offering clear and comprehensive answers.

The survey questionaire was made on a sample of 95 respondents from the wider Banjaluka region, and it was conducted through e-mail. The choice of e-mail as the instrument was justified by focusing on active internet users. Through processing of the collected empirical structure, we attain the structure of respondents according to the frequency of received answers, with the following layout:

Distribution of received answers presents a platform

\begin{tabular}{|c|c|c|c|c|c|c|c|}
\hline Answer / Question & Up to 25 & $25-35$ & $35-45$ & $45-55$ & $55-65$ & $\begin{array}{l}65 \text { and } \\
\text { above }\end{array}$ & Total \\
\hline 1 & 6 & 27 & 25 & 18 & 12 & 7 & 95 \\
\hline Answer & $a$ & $b$ & $c$ & d & - & - & Total \\
\hline 2 & 47 & 25 & 18 & 5 & - & - & 95 \\
\hline Answer & $a$ & $b$ & $c$ & $d$ & $e$ & - & Total \\
\hline 3 & 4 & 16 & 21 & 37 & 17 & - & 95 \\
\hline Answer & $a$ & $b$ & $c$ & - & - & - & Total \\
\hline 4 & 59 & 32 & 4 & - & - & - & 95 \\
\hline Answer & $a$ & $b$ & c & $d$ & - & - & Total \\
\hline 5 & 17 & 22 & 13 & 43 & - & - & 95 \\
\hline Aswer & $a$ & $b$ & c & $d$ & e & $f$ & Total \\
\hline 6 & 9 & 18 & 7 & 3 & 2 & 13 & 52 \\
\hline Answer & $a$ & $b$ & c & $d$ & - & - & Total \\
\hline 7 & 34 & 8 & 4 & 6 & - & - & 52 \\
\hline Answer & $a$ & $b$ & c & $d$ & $e$ & $f$ & Total \\
\hline 8 & 5 & 17 & 6 & 13 & 2 & 9 & 52 \\
\hline Answer & $a$ & $b$ & c & $d$ & $e$ & $f$ & Total \\
\hline$I$ & 3 & 11 & 6 & 13 & 17 & 2 & 52 \\
\hline$I I$ & 13 & 5 & 3 & 7 & 6 & 3 & 37 \\
\hline
\end{tabular}

Table 1. Cumulative survey result - distribution of frequency of respondent answers through questions; distribution of answers to question no. 9 is divided into two groups, as follows: I - respondents who had used the internet trading service and II - respondents who had not used it (multiple answers to question no. 6 include answers $(\mathrm{a}+\mathrm{b})$ from 4 respondents, answers $(b+c)$ from 5 respondents, answers $(a+c)$ from 3 respondents and answer $(b+e)$ from one respondent, where the one answer under e refers to Aliexpress in the additional explanation; multiple answers to question no. 8 include answers $(b+d)$ from 5 respondents, answers $(a+b)$ and $(a+d)$ from 2 respondents each; multiple answers to question no. 9 in both cases include answers $(b+e)$, in group I, and in group II two times $(a+e)$ and once $(b+e))$ 
for the analysis of potential consumers in reference to frequency of chosing internet trading as the preferred distribution channel and perception of the realized or desired quality through the interned trading service. The important aspect of analysis refers to adequate insight of a portion of the conquered available market on one hand, as well as the realized level of user satisfaction from the consumed service, and the cause-and-effect connection between the source of (dis)satisfaction of the respondent through perception of realized quality of provided service and the preference of consumer determination.

The initial analysis foundation refers to comprehending the representation of internet trading, as a distribution channel, The participation of respondents who used the internet trading service is shown in Image 1.

\section{Frequency of preferred distribution channel}

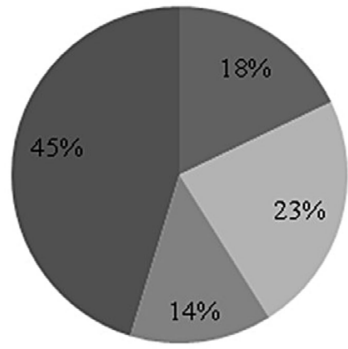

$$
\begin{aligned}
& \text { घa. Quite often (several } \\
& \text { times per year) } \\
& \text { b. Often (every year) } \\
& \text { ac. Ocasionally (less then } \\
& \text { every year) } \\
& \text { a. Seldom or never (do } \\
& \text { not remember when) }
\end{aligned}
$$

Image 1. Structure of respondents according to personal preferences in reference to internet trading as distribution channel

The logical continuation of the analysis includes overviewing the realized satisfaction level for the provided service, displayed in Image 2 .

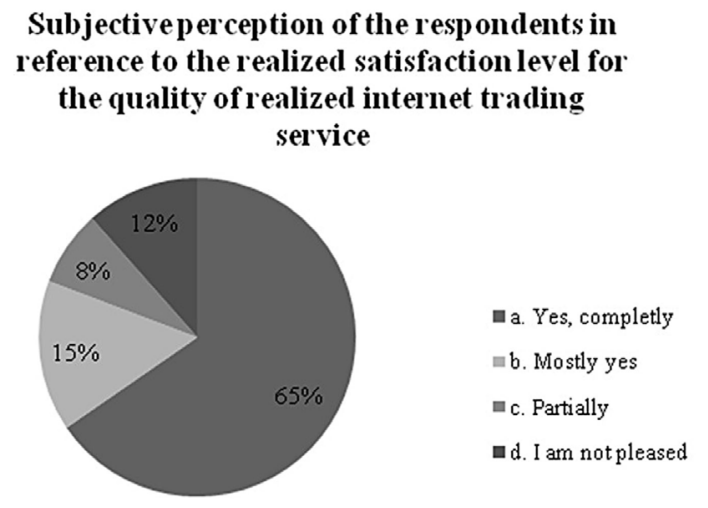

Image 2. Distribution of respondents according to subjective perception of the respondents in reference to the realized satisfaction level for the quality of realized internet trading service
Having in mind an extremely low percentage of users with high satisfaction preferences for the realized internet trading service, it is justified to shed some additional light on the causes of such a result. Distribution of causes for dissatisfaction of respondents with the quality of internet trading service may be illustrated through the following pie chart:

\section{Sources (causes) of users dissatisfaction with the quality of internet trading service}
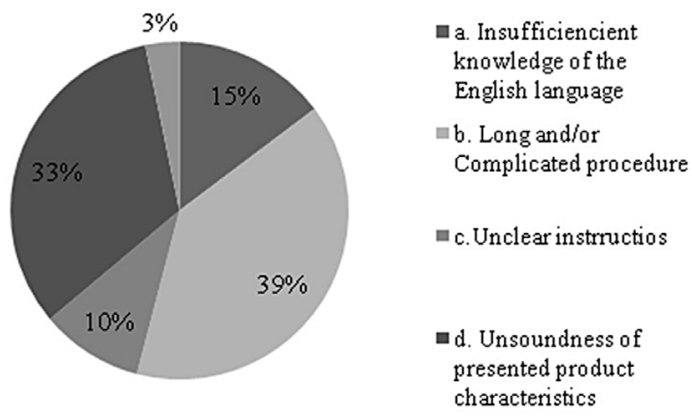
Image 3. Structure of respondents according to the cause (source) of dissatisfaction with the quality of realized internet trading service.

Previous illustrations of respondent distribution according to frequency of received answers, enable their adequate appreciation in the procedure of formulation of optimal development strategies.

\section{STOCHASTIC CORRECTION OF THE LEVEL OF QUALITY OF INTERNET TRADING SERVICE}

Measuring and expressing the degree and direction of alliance between two appearances presented by couples of rank variables, presents the platform of application of Spearman's coefficient of rank correlation. The analysis starts with the precondition that there are no linked value couples for which the intensity of interdependence is calculated, which refers to harmonization of shopping frequency with the proposed measures for increasing of the satisfaction level with the service users.

An important aspect of this research also refers to examining the compliance between forms of distribution of sources for upgrading the quality of service with its existing and potential users. The aforementioned analysis is realized efficiently by the use of $\chi^{2}$ test for independence of insignia in the contingency table (Šošić, 1998). 


\section{THE DEGREEAND DIRECTION OF QUANTITATI- VE MATCHING OF VARIATIONS OF THE PERCEP- TION OF THE SOURCE OF (DIS) SATISFACTION WITH INTERNET TRADING SERVICE DEPEN- DING ON THE FREQUENCY OF ITS USAGE}

The value of Spearman's coefficient of rank correlation, as the measure for stating the perception of source of dissatisfaction of service users depending on the frequency of its usage, in the specific case is 0.734388 , which indicates a significant uniflow degree of quantitative matching of variations of the aforementioned appearances, whose statistical significance we test through the following protocol:

a. Statistical hypotesis is formulated through definitions: $\mathrm{H}_{0}$ : rWe determine table value with $99 \%$ reliability, i.e. error risk 1\%, by using the Student's $t$ distribution of probability, which in the observed case carries the value of : $\mathrm{t}_{0,005 ; 90}=2.6316$ (Lovrić, Komić, \& Stević, 2006)

b. Calculated test value is: $\mathrm{t}=3,091$ (Landika \& Bojanić, Research and analysis, 2016);

c. Bearing in mind the fact that the table value is below the test value, we reject the precondition contained in the null hypotesis, with 99\% reliability (Šošić, 1998).

6. COMPLIANCE OF PERCEPTION FOR SOURCES OF POTENTIALUPGRADES OF INTERNET TRADING SERVICE QUALITY WITH RESPONDENTS WHO HAVE (NOT) USED THE LATTER

a. Metric comparison of perception of realized and/ or assumed sources for upgrading the internet trading service is realized efficiently by application of the cStatistical hypotesis is formulated by definitions: $\mathrm{H}_{0}$ : distribution of frequency of source of (dis)satisfaction is not different between users and those who do not use the service; $\mathrm{H}_{\mathrm{a}}$ : distribution of frequency of source of (dis)satisfaction is different between users and those who do not use the service;

b. We determine the table value with $99 \%$ reliability, i.e. $1 \%$ risk, amounts to $\chi_{0,01 ; 4}^{2}=13.277$;

c. The calculated test value is calculated by the use of the following formula: $\mathrm{t}=r_{S} \cdot \sqrt{\frac{n-2}{1-r_{s}^{2}}}$. (Landika, 2015 ), and it amounts to $t=3.091$, with the Spearman's coefficient of rang correlation is calcuated by using the following expression: $r_{s}=1-\frac{6 \sum_{i=1}^{n} d_{i}^{2}}{n^{3}-n}$, while its value is $r_{s}=0,734388$ (Landika \& Bojanić, 2016)

d. With appreciation of the fact that the table value is below the test one, we reject the precondition contained in the null hypotesis, with $99 \%$ reliability (Šošić, 1998).

\section{FINAL CONSIDERATIONS}

The research framework of the used descriptive inferential statistical analysis, grounds the management platform with the following strategic contents:

- Representation of internet trading amongst distribution channels results (Image 1) is not at a satisfactory level with users at the chosen market segment. There is a high percentage of respondents, $59 \%$ of them, who never or rarely use this distribution channel;

- On the other hand, there is a high portion of $70 \%$ of respondents with a high degree of subjective perception of the realized quality level of internet trading service, which results from the structural circle of empirical series (Image 2). The aforementioned findings can and need to be exploited in the process of formulation of development strategy for this distribution channel.

- The previous quotation and conclusion can be ammended by sources (causes) of dissatisfaction among users of internet trading services, as is clearly illustrated by the structural circle of empirical series (Image 3), where the "long and/ or complicated procedure" and "unsoundness of the presented characteristics" are shown as dominant, with frequency of $39 \%$ and $33 \%$, i.e. with $72 \%$ of respondents. The noted cognition can also and would be usefully exploited in the procedure of formulation of optimal development strategy for this distribution channel;

- Subjective valorisation of the realized level of internet trading service quality displays a direct correlation between 0.734388 strenght degree and frequency of its realization. The direction and strength of the noted causality represents a significant postulate and an adequate tool for managing the behaviour of both existing and potential users;

- Subjective perception of the source for improvement of the realized, i.e. assumed level of internet 
trading service quality, displays a high degree of discrepancies, thereby opening a possibility for removing and overcoming the actual potential sources of user dissatisfaction.

The utilised tools of descriptive statistical analysis include a table layout of distribution of received answers in relation to the conducted survey protocol, and graphic layout of distribution of respondent preferences with regards to selection of distribution channels, source of (dis)satisfaction and perception of potential sources for upgrading of internet trading service by using the structural circle.

The inferential statistical analysis includes the Spearman's coefficient of rank correlation, and the $\chi^{2}$ test, whose application enables an objective approach to the analysis of quality of results of tested processes by adjusted metrics, as well as the qualitative adjustment to real systems. Segmented diversity within the global system is emphasized through certain specifics, which require a subtle approach to segmenting and recognition of characteristics of the system units.

The effects of implementation of results of analysis and tests overwhelmingly exceed the costs of obtaining a management platform, which include collecting and statistical processing of empirical structure, while the efficiency degree is greatly alleviated by means of an adequate IT structure.

\section{BIBLIOGRAPHY}

Landika, M. (2015). Metodi statističke analize - primjena u oblasti zdravstvenih, sportskih $i$ inžinjerskih nauka. (Methods of Statistical Analysis - Implementation in the field of healthcare, sports and engineering sciences) Banja Luka: Paneuropean University Apeiron.

Landika, M., \& Bojanić, R. (2016). Istraživanje i analiza (Research and Analysis). Banja Luka.

Lovrić, M., Komić, J., \& Stević, S. (2006). Statistička analiza, metodi i primjena.(Statistical Analysis, Methods and Implementation) Banja Luka: Faculty of Economy.

Šošić, I. (1998). Zbirka zadataka iz statistike. (Collection of Statistics Assignements) Zagreb: Faculty of Economy.

Todorović, J. (2001). Strategijski i operativni menadžment. (Strategic and Operational Management) Belgrade: Faculty of Economy. 